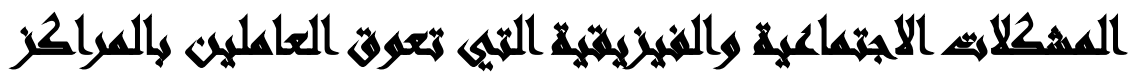

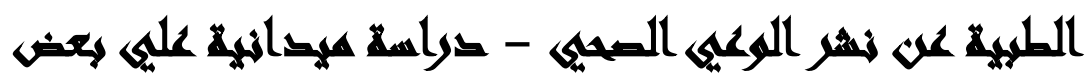

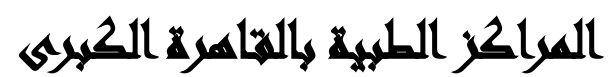

\section{[1r]}

مصطفي ابراهيم عوض(') - أحمد عصمت شومان(') - سماح عبد الرحيم قمصان

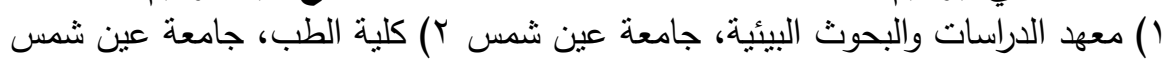

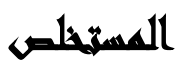

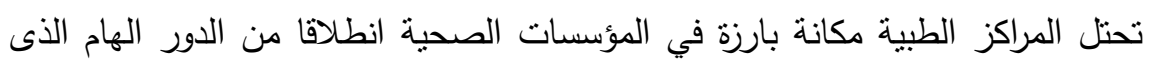

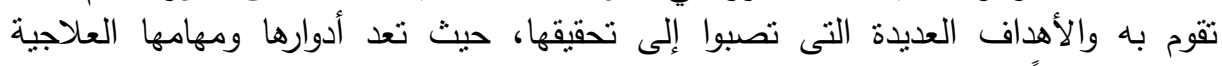

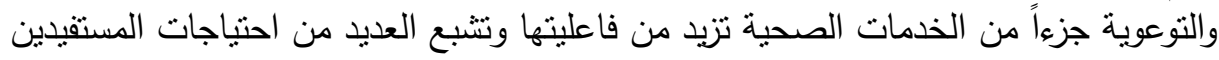

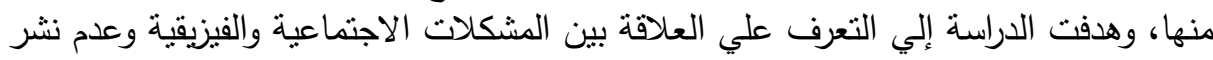

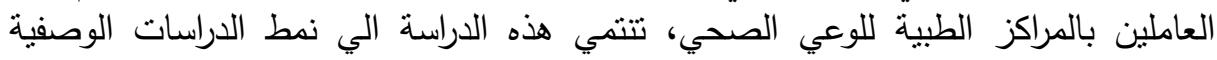

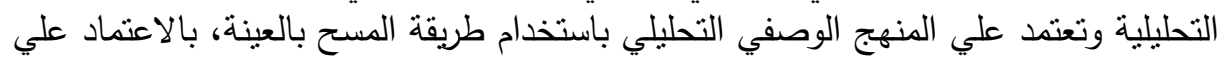

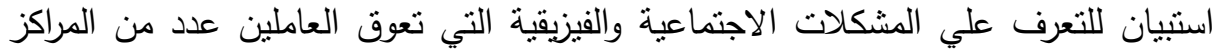

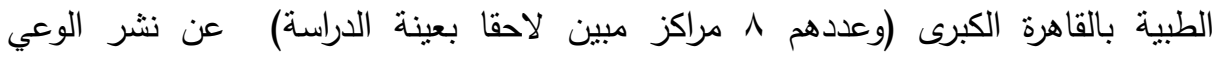

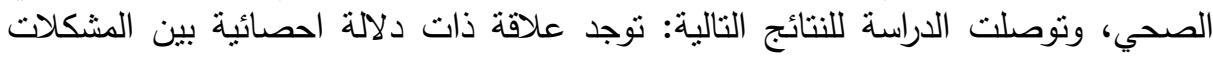

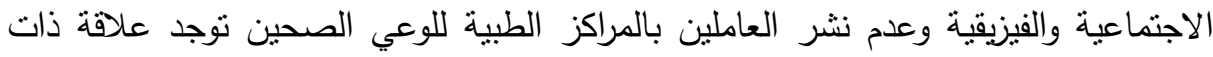

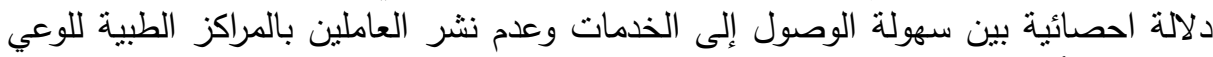

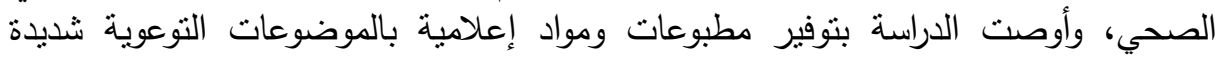

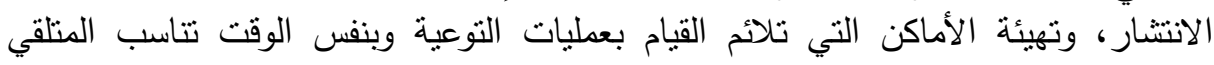
ليتسنى الاستفادة بالصورة المرجوة.

\section{$\operatorname{xan}$}

يقصد بالرعاية الطبية الخدمات النتخيصية والعلاجية والتأهيلية والاجتماعية والنفسية

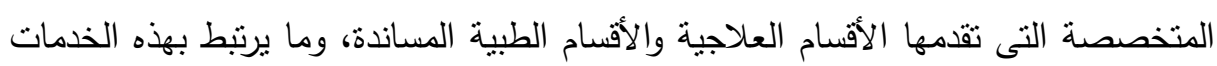

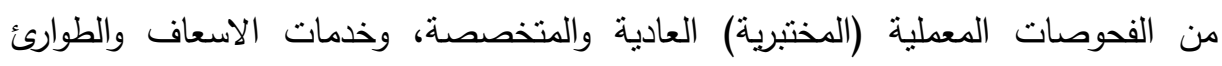

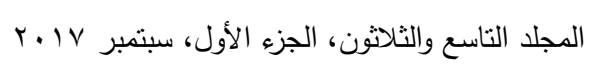


وخدمات التمريض والخدمات الصبدلانية والغذائية ومما لاشك فيه أن الرعاية الطبية تمثل الوظيفة الأولى التى تحظى بالاهتمام الأكبر في جميع المراكز الخاصة منها والحكومية على لهى

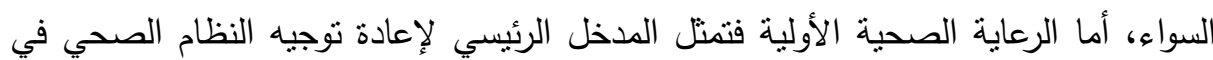

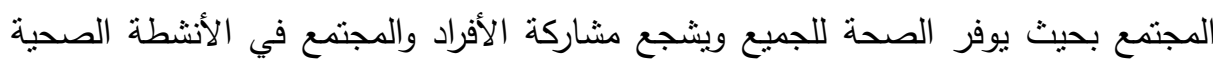

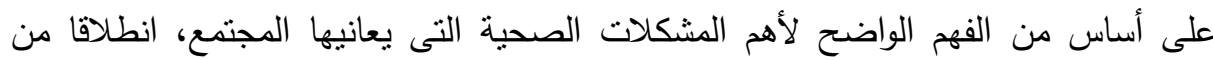

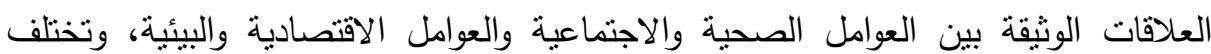
أنثطة ومجالات الرعاية الصحية باختلاف ظروف البيئة المحلية في الدول المختلفة(بدران بن

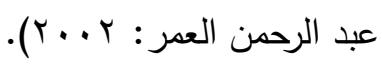

وجهت منظمة الصحة العالمية قلقها على قدرة العديد من دول العالم النامي في الحصول

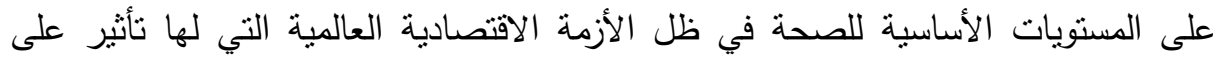
القطاع الصحي من نتظيم أسرة وخدمات صحية أساسية لأفراد المجتمع. (Kelley lee, Kent Buse : 2002,P 5)

وتقوم المراكز الطبية على أهداف عدة يرجع البعض سبباً لوجودها - ومن هذه الأهداف

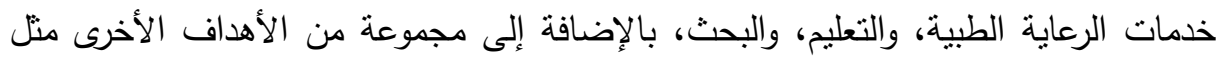
تحقيق الاستقرار الاقتصادي والمحافظة على خفض التكاليف مع تقديم الرعاية والخدمة

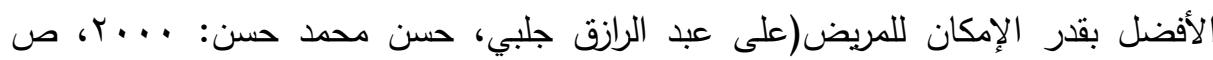

تحتل المراكز الطبية مكانة بارزة فى المؤسسات الصحية انطلاقا من الدور الهام الذى

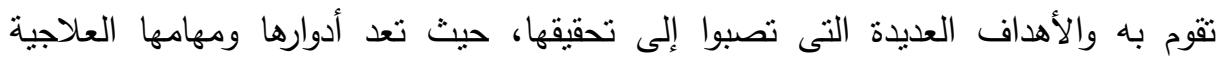
والتوعوية جزءاً من الخدمات الصحية تزيد من فاعليتها وتتبع العديد من احتياجات المستقيدين

ونلاحظ أن لكل مؤسسة صحية أهدافاً تقوم على أساسها لا تختلف كثيراً عن أهداف المؤسسة الصحية الأخرى، ولكن نجد أهدافاً أساسية يشترك بها كل تلفي تلك المؤسسات المعنية برعاية المريض، فمن الملاحظ أن المراكز الطبية تكون لها أهداف تتلاءم مع الخدمات 
المطلوب تقديمها سواء كانت علاجية أو توعوية للمجتمع الذي تقوم علي خدمته، ومن أهداف

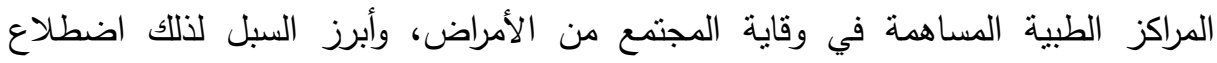

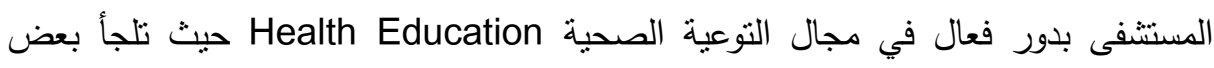
المراكز إلى تتظيم ندوات للمرضى وذويهم لتوعيتهم بجوانب الصحة والمرض والعادات المؤدية إلى المرض وسبل المحافظة على الصحة.

\section{مئمالة التراسة}

قام الباحثُون باستعراض عدد من الدراسات مثل:

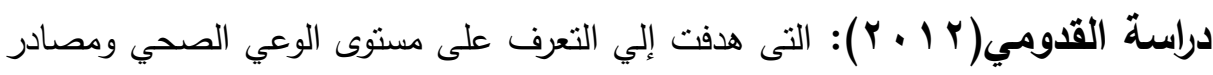

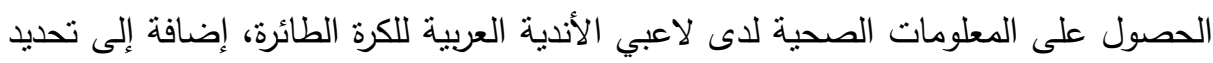
الفروق في مسنوى الوعي الصحي تبعا لمتغيري الخبرة في اللعب والمؤهل العلمي للى الديه

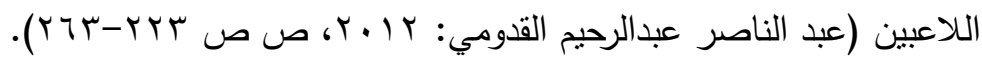

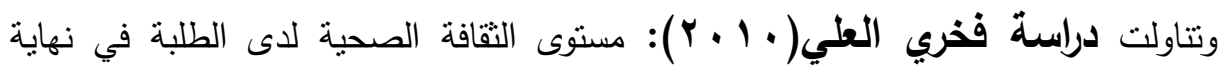
المرحة الأساسية العليا في المدارس الحكومية في جنين، إضافة إلى تحديد أثر متغيرات

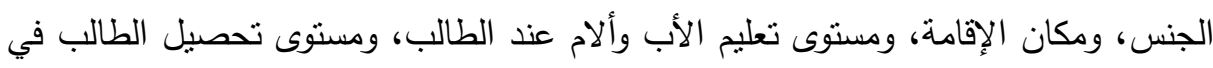

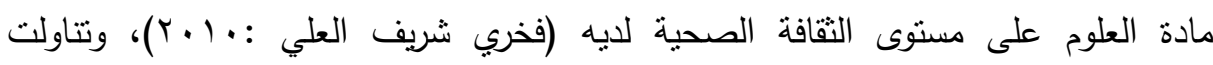

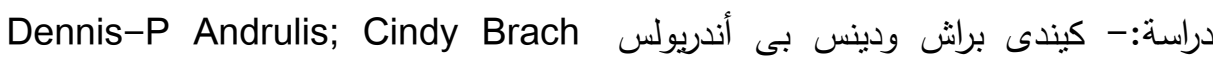

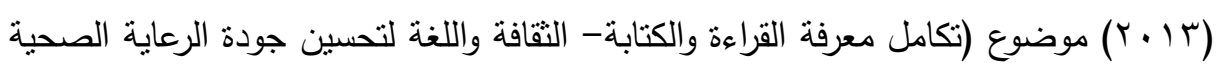

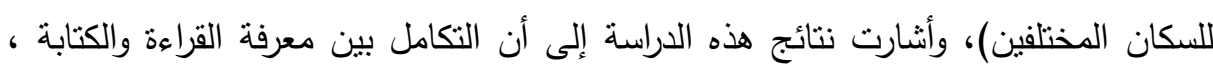

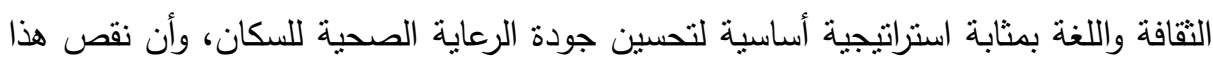
التكامل يؤثر سلبيا على جودة الرعاية الصحية.-Andrulis,-Dennis-P; Brach, . Cindy ;(2013) Vol 31)

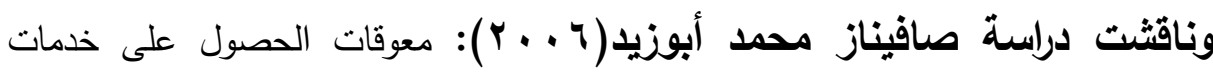
الرعاية الصحية بالمستشفيات العامة، ومعوقات تقديمها، ومقترحات لتطويرها، وأنثارت نتائج

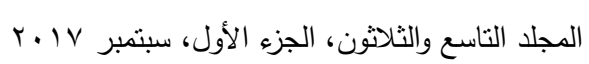


الدراسة إلى أن من أهم معوقات الحصول على خدمات الرعاية الصحية بالمستشفيات العامة سوء علاقة الطبيب، الخدمة التمريضية غير الجيدة، صعوبة الحصول على الأدوية من صيدلية المستشفى، الخدمة الغذائية غير الجيدة، عدم تتوع الأطعمة المقدمة للمرضى، ومن عنديه أهم معوقات تقديم الخدمة منها ما هو متعلق بالأطباء، والممرضين والأخصائيين

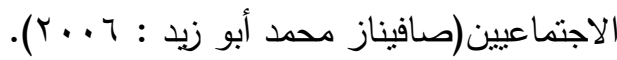

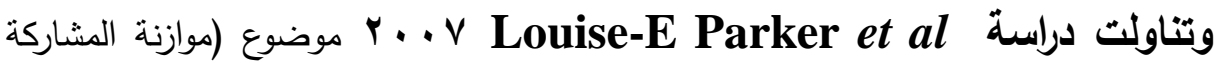
والخبرة : دراسة مقارنة بين تحسين جودة الرعاية المدارة محليا ومركزيا داخل ممارسات الرعاية الصحية الأولية)، واستهدفت هذه الدراسة تقييم طريقتين لتحسين جودة الرعاية الصحية إحداهما تؤكد المشاركة (المدخل المحلى) والثانية الخبرة (المدخل المركزي)، وأوضحت نتائج

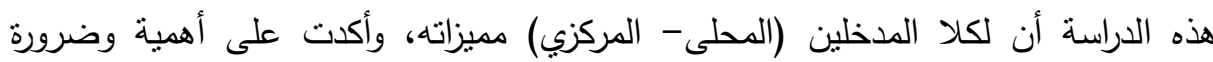

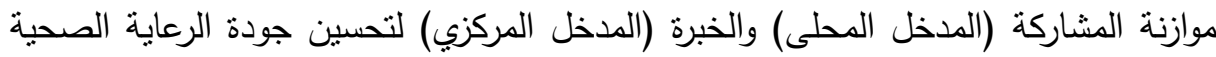
الأولية، على أساس أن هذه الموازنة تقدم أفضل صيغة للتحسين المستمر للجودة بمنظمات الرعاية الصحية، حيث أن الخبرة تركز على القرارات الاستراتيجية حول ماهية الممارسات التي يجب تبنيها، بينما المدخل المحلى يركز على القرارات التكتيكية حول التتفيذ. Louise-E)

Parker et al : 2007)

ومن العرض السابق تبين للباحثون أهمية التوعية الصحية ومستوي جودتها والعوامل التي يمكنها أن تؤثر في عملية التوعية الصحية، فالتثقيف الصحي والبيئي وعملية نشر الوعي التئي

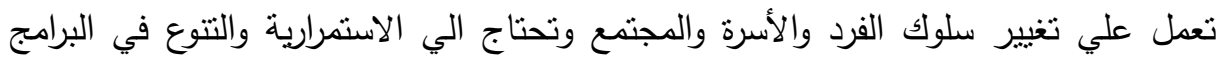

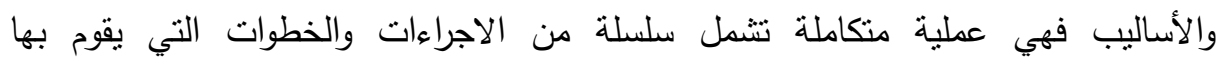
الأشخاص للوصول الي النتائج المرجوة، ولما كانت نللك العملية تواجه العديد من المعوقات والمشكلات التي تحول دون تحقيق عملية نشر الوعي لأهدافها المرجوة، فقد رأت الباحثة أنه

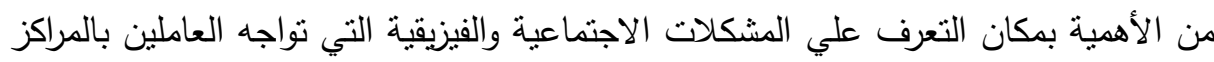
الطبية وتعوقهم عن نشر الوعي الصحي. 


\section{مهاسهيه الصراسة}

ا- الوعي الصحي: يعني تثقيف الأفراد واثارة وعيهم لغرض تغيير سلوكهم وعاداتهم خاصة في حالة انتشار الأمراض داخل المجتمع، وكذلك غرس العادات والثقاليد الاجتماعية التي من شأنها تدعيم الجانب الصحي وتطوره مثل ممارسة الرياضة والتغذية

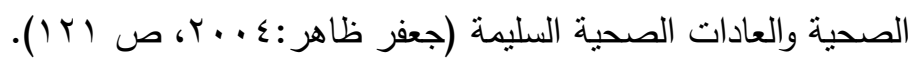

r- المشكلات الاجتماعية يعرفها الباحثون في الدراسة الحالية بأنها المشكلات التي تواجه العاملين بالمراكز الطبية وتعوقهم عن نشر الوعي الصحي، وتتعلق هذه المشكلات

$$
\text { بالمستوي التعليمي والتقافي وحجم الدخول. بالمان. }
$$

r- المشكلات القيزيقية: يعرفها الباحثون في الدراسة الحالية بأنها المشكلات التي تواجه العاملين بالمراكز الطبية وتعوقهم عن نشر الوعي الصحي، وتتعلق هذه المشكلات بالتجهيزات والإضاءة والمباني والمنشآت التي تقدم فيها الخدمات الصحية والتوعوية التي لتهري

تقدمها المراكز الطبية.

\section{أهمية التصراسة}

\section{1- الأهمية النظرية}

- إثراء أدبيات الدراسات الانسانية حول موضوع الوعي الصحي والمشكلات الاجتماعية

$$
\text { والفيزيقية التي تعوق نشره. }
$$

- ندرة الدراسات التي تتاولت مشكلات العاملين بالمراكز الطبية.

\section{r - ب أهمية تطبيقة}

- تقديم الحلول والمقترحات حول التعامل مع مثل هذه المشكلات. - إمكانية التوصل الي مقترحات من شأنها تكثيف وتفعيل عملية نشر الوعي الصدي هده

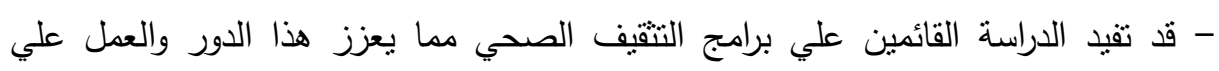
تحسين الخدمات المقدمة. 


\section{أهساهنم التراسة}

الهوف الرئيس: التعرف علي العلاقة بين المشكلات الاجتماعية والفيزيقية وعدم نشر العاملين بالمراكز الطبية للوعي الصحي.

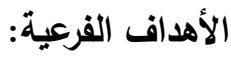

• التعرف علي العلاقة بين كفاءة تقديم الخدمة وعدم نشر العاملين بالمراكز الطبية للوعي الصحي. • التعرف علي العلاقة بين سهولة الوصول إلى الخدمات وعدم نشر العاملين بالمراكز الطبية اللوعي الصحي. • التعرف علي العلاقة بين توفير الرعاية الصحية في الوقت المناسب وعدم نشر العاملين بالمراكز الطبية للوعي الصحي.

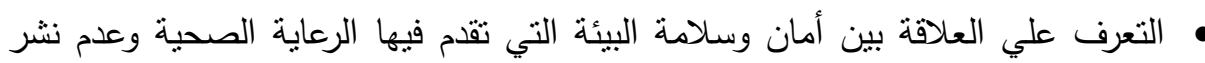
العاملين بالمراكز الطبية للوعي الصحي. • التعرف علي العلاقة بين العلاقات بين أعضاء الفريق الصحي وعدم نشر العاملين بالمراكز الطبية للوعي الصحي. • التعرف علي العلاقة بين البنية التحتية الفيزيائية ووسائل الراحة وعدم نشر العاملين بالمراكز الطبية للوعي الصحي.

\section{هغوض القراسما}

الفرض الرئيس: توجد علاقة ذات دلالة احصائية بين المشكلات الاجتماعية والفيزيقية وعدم نشر العاملين بالمراكز الطبية للوعي الصحي. الفروض الفرعية

1- توجد علاقة ذات دلالة احصائية بين كفاءة تقديم الخدمة وعدم نشر العاملين بالمراكز

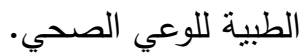


r- توجد علاقة ذات دلالة احصائية بين سهولة الوصول إلى الخدمات وعدم نشر العاملين بالمراكز الطبية للوعي الصحي. r- نوجد علاقة ذات دلالة احصائية بين توفير الرعاية الصحية في الوقت المناسب وعدم نشر العاملين بالمراكز الطبية للوعي الصحي. ع - توجد علاقة ذات دلالة احصائية بين أمان وسلامة البيئة التي تقدم فيها الرعاية الصحية لهية وعدم نشر العاملين بالمراكز الطبية للوعي الصحي. ه- توجد علاقة ذات دلالة احصائية بين العلاقات بين أعضاء الفريق الصحي لوعي وعدم نشر العاملين بالمراكز الطبية للوعي الصحي. 1- توجد علاقة ذات دلالة احصائية بين البنية التحنية الفيزيائية ووسائل الراحة وعدم نشر لتربر العاملين بالمراكز الطبية للوعي الصحي.

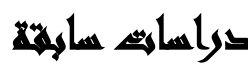

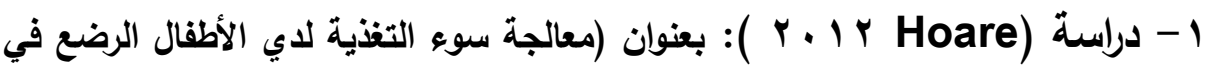
جامبيا): في دراسة سوء التغذية للأطفال حديثي الولادة في جامبيا، قدرت منظمة الصحة

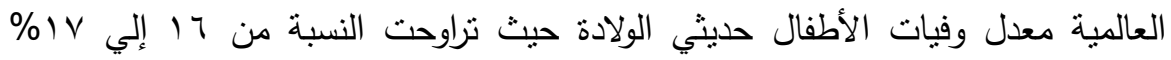
ونسبة وفيات الأطفال بسبب سوء التغذية لأقل من خمس سنوات هب\% في جامبيا. اقترح الباحث نظام صحي أولي تعليمي يركز علي الأطفال حديثي الولادة في منطقة ما بجامبيا،

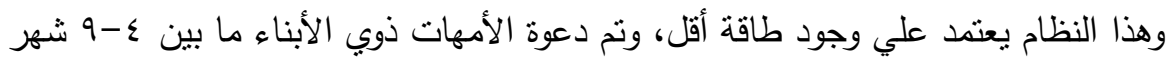
لشرح هذا النظام لهم ، وقد صادفه انتقادات بسبب العادات المتخصصة من أطباق الغذاء لزيادة المحتوي الغذائي، واستطرد الباحث أن استخدام هذا النموذج أو البرنامج قد أدي لهي

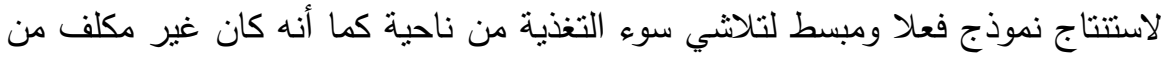
ناحية أخري.) (Hoare K; ; (2012) r - دراسة لوتس ( Lottes, ) . . . بهدف تحليل فائدة نظام صحي في كلية جتزبيرج، حيث ركزت الدراسة على السؤالين ما الذي يؤدي إلى زيادة معرفة الطلبة في

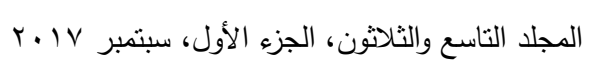


أحداث تغير في سلوكهم في نهاية المساق الصحي؟ ماذا يقول الطلبة عن تأثيرات المساق

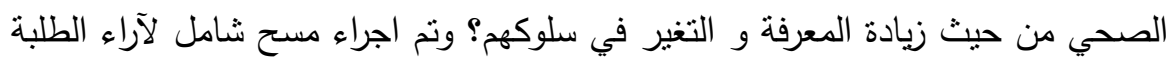

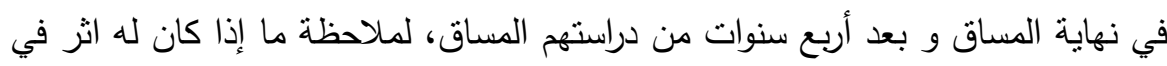
نمط حياتهم الصحي و قد بينت الدراسة إن التغيرات السلوكية التي حدثت في نهاية المساق وبعد أربع سنوات من دراسة المساق كانت إدارة الوقت و التغذية و التغلب على التى

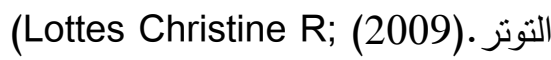

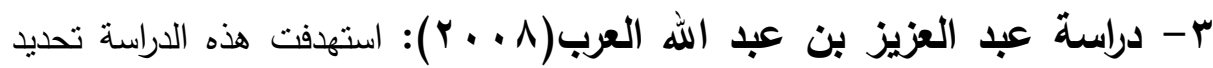
مدى تطبيق المستشفيات الخاصة لإدارة الجودة الثشاملة وذلك من وجهة نظر المسئولين بتلك المستشفيات، وأوضحت نتائج الدراسة أن المستشفيات الخاصة تطبق إدارة الجودة، وأن المستشفيات الخاصة تهتم بتحسين جودة الخدمات الصحية، وأوصت الدراسة بضرورة اهتمام المستشفيات الخاصة بوضع خطط استراتيجية وسياسية للجودة الثشاملة، وضرورة الاهتمام بالتدريب المستمر والمننظم لرفع كفاءة العاملين بها (عبد العزيز بن عبد اله

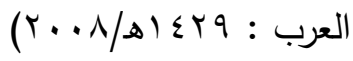

ع - دراسة عصام الاين حلمى 1 . . ץ : أوضحت أن هنالك ضرورة لنتنى المستشفيات الحكومية لأسلوب إدارة الجودة الثاملة بهدف تحسين مستوى الأداء الطبي والإداري بالمستشفيات، وذللك من خلال إعداد برامج تدريبية وتعليمية عن الجودة الثاملة والتعرف على احتياجات ورغبات العملاء لجميع العاملين بالمسنشفيات الحكومية وأكدت على أهمية اعتتاق مفاهيم مبادئ الجودة الثاملة وزيادة درجة الولاء والانتماء للعاملين، وأهمية بناء نظام الحوافز وأن يكون الحوافز على نظام قدر العمل، وضرورة مشاركة العاملين للعمل

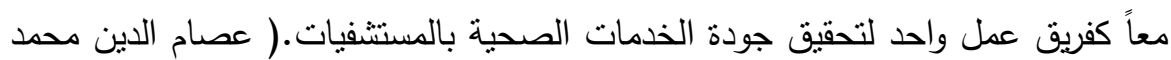

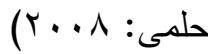

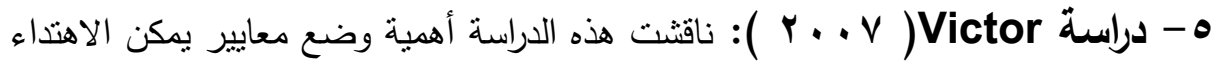
بها فى مختلف المستشفيات، تتم الإشارة إلى هذه المعايير باعتبارها التقنية التى تقيس من

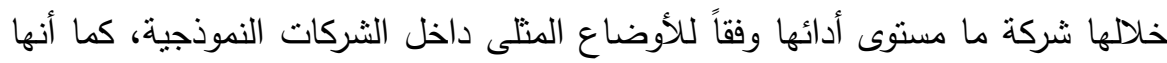


تحدد كيف أن هذه الثركات وصلت لهذه المستويات من الأداء بالإضافة إلى أنها تستخدم المعلومات المتاحة لديها بغرض الارتقاء بمستوى أدائها، وتتشمل المفردات التى من الممكن الإدهن الاهتداء بها فى الاستراتيجيات والممارسات التى يتم تطبيقها، وقد يقيم المرضى داخل بهل

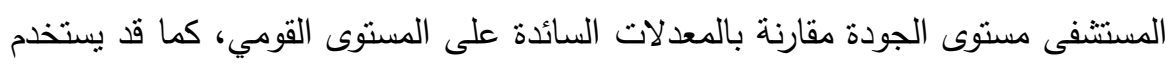

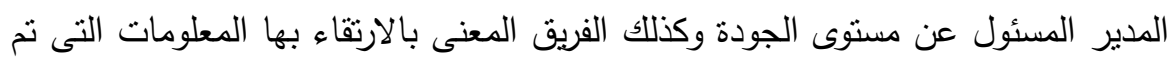
جمعها حول المجالات التى بحاجة ملحة إلى التنخل الفوري بغية الإصلاح والتطور ل

(Sewer, Victor E "Benchmarking in Hospitals : 2007)

\section{الاطار النظظيه}

1 - خصائص الوعى الصحي: يعرف بأنه الإدراك القائم على المعرفة بضرورة حسن استغلال الموارد الطبيعية والمشكلات البيئية مع اقتراح أنسب الأساليب لمواجهة هذه الإدراته

$$
\text { المشكلات (منى حامد على إبراهيم : } 991 \text { (1، ص ع ؟ب). }
$$

وبأنه: وجود مدركات ومهارات لدى الفرد يستخدمها للعمل فردياً واجنماعياً للمحافظة على الاتزان الديناميكي بين الحياة ونوعية البيئة التى يعيش فيها الفرد(هبة أحمد صالح

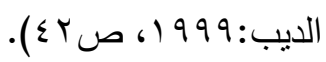

ومن خلال تعريفات الوعى الصحي يتضح أن له خصائص عديدة منها:

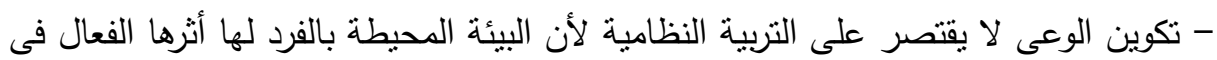

$$
\text { - الوعى الصحي يتضمن تلازم الجانبين المعرفي والوجداني. }
$$

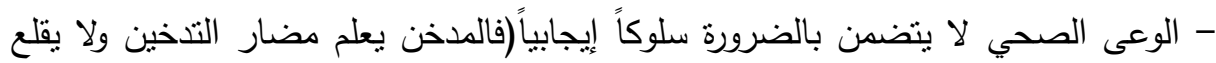
عنها. - الوعى الصحي هو الخطوة الأولى في تكوين الاتجاهات البيئية التى تتحكم فى سلوك الفرد. -الوعى الصحي وظيفة تتبؤية عما يمكن أن يصدر من سلوك الفرد تجاه صحته البدنية

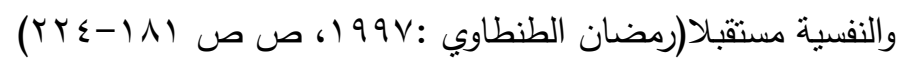

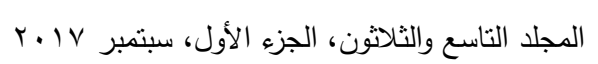


r - مستويات الوعى الصحي: الوعى الصحي: يختص بالثعور والإحساس والإدرالك بالبيئة المحيطة بالإنسان. وهو مستويان: - المستوى المعرفي: يختص بجميع المبادئ والمعارف والمفاهيم والعلاقات المتبادلة بين الإنسان والبيئة والتعرف على المشكلات البيئية. - المستوى المهارى: مهارة التفكير فى تقدير عظمة الخالق - سبحانه وتعالى - فى جعل البيئة فى حالة اتزان طبيعي ومعرفة سلوك الفرد غير الرشيد الذى أدى إلى اختلال النوازن الطبيعي، وإحداث المشكلات البيئية ومهارة التفكير فى العمل على حل هذه المشكلات، ومهارة اتخاذ القرارات الإيجابية لنع ظهور هذه المشكلات. وهناك نوعان أساسيان للوعى الصحي هما: أ) وعى فردى: وهو وعى الإنسان الفرد بظروفه الخاصة وهو محدد فى ضوء أواء الظروف الشخصية لحياة الفرد ونشاطه ووسطه الحياتي اليومي المباشر . ب) وعى جماعي أو جماهيري: وهو وعى طبقة محددة أو فئة اجتماعية أو المجتمع باسره والعلاقة معه، والوعى الجماعي هو أرقى المستوبين وقد سماه دور كايم "وعى الوعى" ويحتوى الوعى الجماعي على وعى الأشخاص وهو بذللك أكثر عقلانية ومنطقية وأرقى

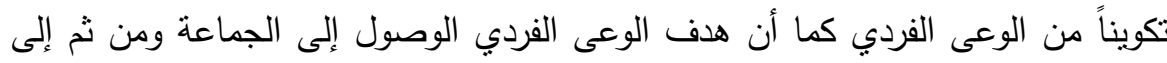

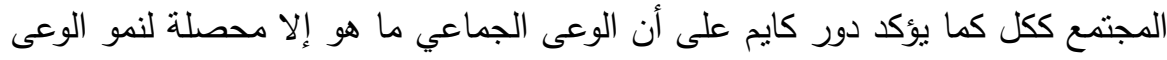

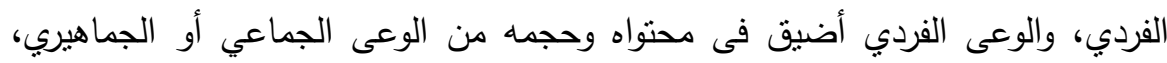

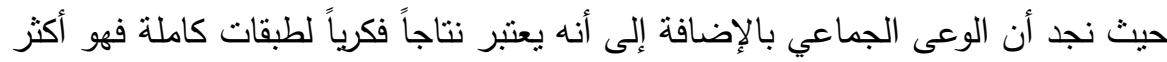

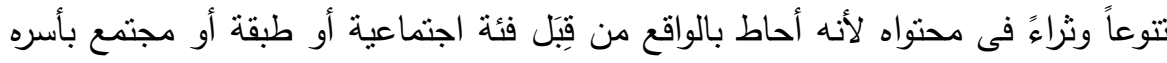

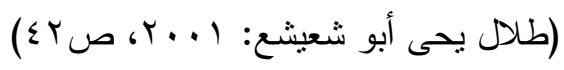

r - أهداف الوعى الصحي: للوعى أهداف متعددة تختلف باختلاف الظروف البيئية التى

$$
\text { يعانى منها كل مجتمع ومن هذه الأهداف: }
$$

- التأكيد على اكتساب بعض القيم والاتجاهات وجوانب التقديرات باستلال بعض الته المهارات التى تمكن الأفراد من إعادة تدوير المخلفات لتعيد للبيئة اتزانها. 
- تغيير سلوك الأفراد تجاه البيئة تغييراً إيجابياً نتيجة لمرورهم ببعض المواقف البيئية التى تساعدهم على اتخاذ القرارات فى المستقبل.

- استغلال مهارة التفكير العلمي في حل المشكلات البيئية فى ضوء ما ينوفر من معارف ومعلومات وحقائق عن البيئة.

- الممارسة الإيجابية لحل بعض المشكلات البيئية والاستفادة بجميع الموارد البيئية الدائمة

$$
\text { وغير المتجدة:(منى حامد على إبراهيم: } 991 \text { (1)، صل . . (1). }
$$

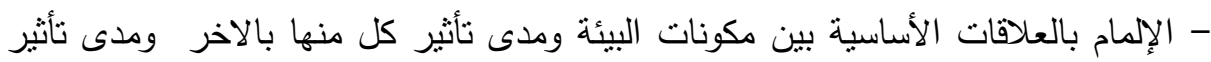
الإنسان عليها.

- الوصول بالإنسان إلى درجة يفهم معها الكيفية التى بها يستخدم الموارد البيئية بحيث يضمن

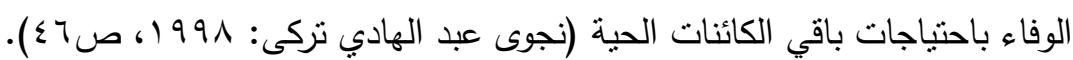
- التوعية بالطرق الصحيحة والسليمة لاستغلال هذه المصادر ، والحد من الاستغلال السيء الذى يؤدى إلى استتزاف، ومساعدة الأفراد على تحمل مسئولياتهم تجاه البيئة. - الفهم الصحيح للمصادر الطبيعية ومعرفة أهميتها. - التخطيط قبل استثمار موارد البيئة بالطريقة الصحيحة والسليمة.

\section{ع - أهمية الوعى الصحي:}

- تكمن أهمية الوعى الصحي فى ضرورة الحرص على البيئة والحد من تدهورها، ومواجهة

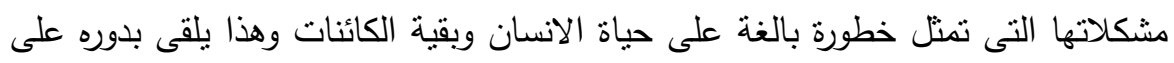

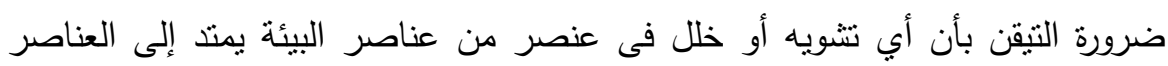

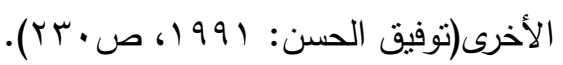

- تزداد أهمية الوعى الصحي حالياً نظرا للنقص الثنديد فيه مع الأوضاع الاقتصادية التصاية

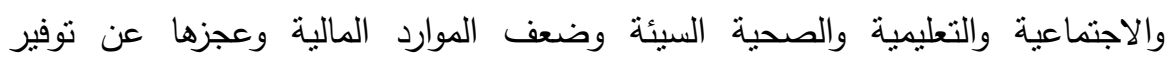
الاحتياجات الأساسية للسكان حتى تسود ثقافة الفقر وترتفع معدلات الأمية وتتدنى الخدمات الاجتماعية والصحية وتتفاقم مظاهر التلوث والعدوان على البيئة. 
- التوعية الصحية من أهم الأمور التى يوليها الإسلام عناية خاصة ويحمل الإنسان مسئولية

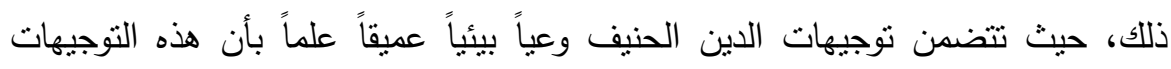
جاءت فى زمن لم تكن مشكلات البيئة فيه تفاقمت وطغت على السطح، فالإسلام يؤكد

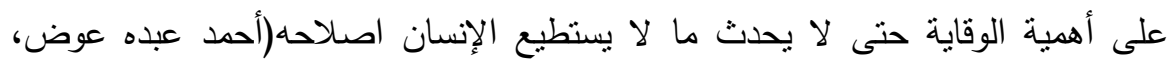

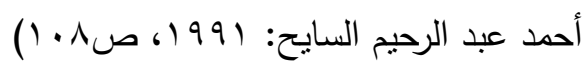

ولا يمكن أن يتأنى ذلك إلا من خلال توعية الأفراد توعية صحية وتربيتهم تربية رشيدة

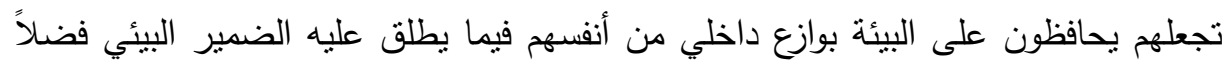
عن أن نقص الوعى بالحقوق والواجبات قد يؤدى إلى تكوين اتجاهات وسلوكيات لدى المواطن تكون ضارة بالنواحي الصحية في مختلف جوانب الحياة. ه - مقومات الوعى الصحي: من العرض السابق للوعى الصحي نجد أن المفهوم الصحيح لله يحتوى على العناصر الأساسية الآتية: - المعرفة والفهم لككونات البيئة الطبيعية وعلاقة الإنسان بها والمشكلات المترتبة على هذها الهيه

- تكوين القيم والاتجاهات الموجبة نحو البيئة وذللك نتيجة لما يحصل عليه المتلقي من معلومات ومعارف بيئية والخروج منها بمفاهيم وتعميمات واتجاهات إيجابية نحو البيئة.

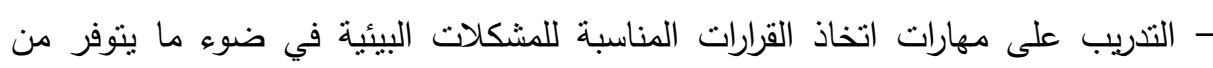
معلومات وحقائق. - المحافظة على البيئة وحمايتها وذلك بالترشيد في الاستهلاك وحسن الاستغلال لمواردها وثرواتها.

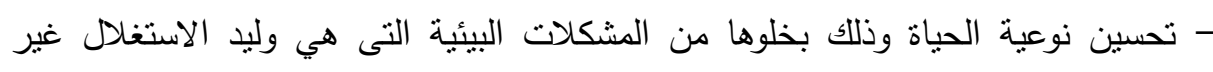
العقلاني لمواردها البيئية ويتم ذلك عن طريق تتشئة الصغار على القيم والاتجاهات البيئية

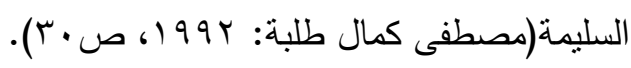




\section{7- - مستويات الوعى الصحي:}

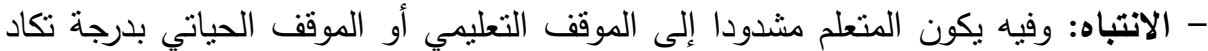

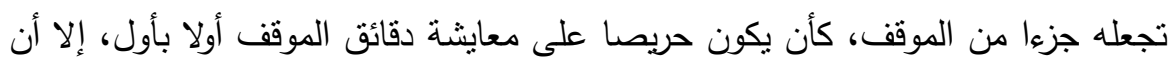

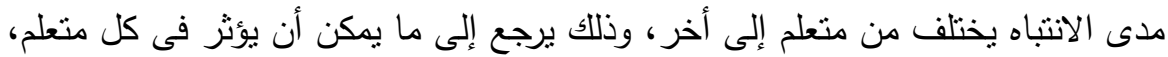

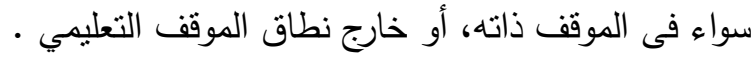

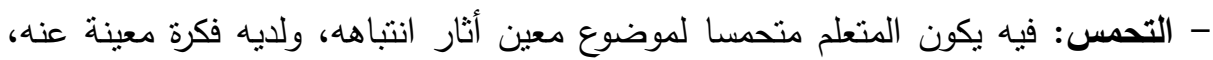

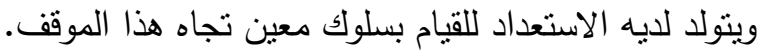

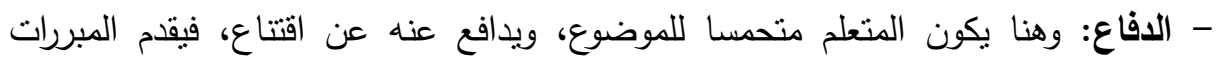

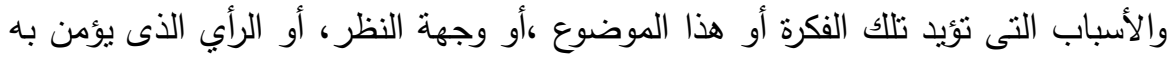

$$
\text { ومن ثم يدافع عنها. }
$$

- التبني: ويعنى الاقتتاع الكامل بالفكرة أو الموضوع، أو الرأي، وفى إطار ذللك يتخذ المعلم

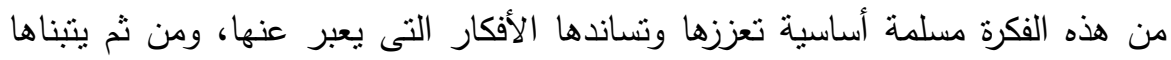

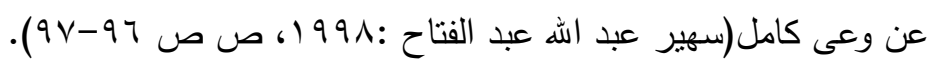

\section{الإجراءايت المنهجية للقداهة}

1- نوع الدارسة ومنهجها: تنتمي هذه الدراسة الي نمط الدراسات الوصفية النحليلية وتعتمد علي المنهج الوصفي النحليلي باستخدام طريقة السسح بالعينة.

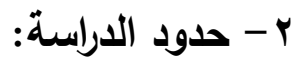
- الحد الجغرافي : عدد من المراكز الطبية بالقاهرة الكبرى كالآتي:

$$
\begin{aligned}
& \text { • مركز طبي منشية السد العالي. } \\
& \text { • مركز طبي الحرفيين. } \\
& \text { • مركز طبي السلام أول. } \\
& \text { • • مركز طبي السلام ثاني. } \\
& \text { • • مركز طبي الدلتا. }
\end{aligned}
$$




$$
\text { • • مركز طبي الطريقي. }
$$

- الحد البشري: عينة من العاملين بتلك المراكز الطبية.

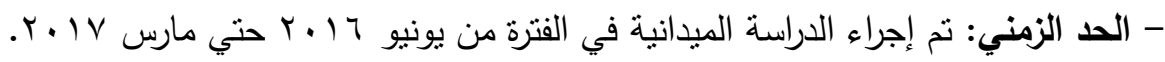

$$
\text { ب- أدوات الدراسة: }
$$

- استبيان للتعرف علي المشكلات الاجتماعية والفيزيقية التي تعوق العاملين بالمراكز الطبية

$$
\text { وتتاول الاستبيان مجموعة الوعي الصحي ( من إعداد الباحثون). }
$$

- البيانات الأولية المتعلقة بالمبحوثين ونتثمل ^ أسئلة حول الاسم والنوع والمؤهل والحالة

$$
\text { الاجتماعية وسنوات الخبرة الوظيفية. }
$$

- كفاءة تقديم الخدمة الصحية ويشمل $\wedge$ أسئلة . - سهولة الحصول علي الخدمات التي يقدمها المركز ويشمل علي V أسئلة. - توفير الرعاية الصحية في الوقت المناسب ويشمل 1 أسئلة. - أمان وسلامة بيئة تقديم الخدمة الصحية ويشمل 1 أسئلة. - العلاقات بين فريق تقديم الخدمة الصحية ويشمل 1 أسئلة . - البنية التحنية ووسائل الراحة بالمركز الطبي ويشمل V أسئلة.

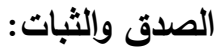

صدق التمييز (المقارنة الطرفية): يشير إلى قدرة المقياس على التمييز بين المجموعات

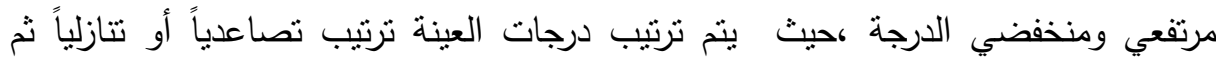
تحديد الارباعي الأعلى(درجات الأفراد مرتفعي الدرجة في المقياس) والارباعي الأدنى(الأفراد

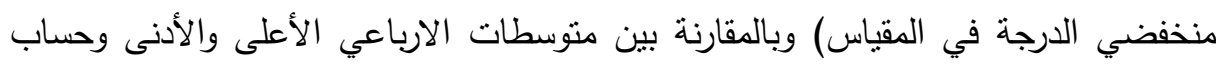
دلالة الفروق بين هذه المتوسطات والجدول التالي يوضح ذلك. 
مصطفي ابراهيم عوض وآخرون

\begin{tabular}{|c|c|c|c|c|c|c|}
\hline مستوي & "ثيمة" & الانحراف المعياري & المتوسط & العدد & المقارزية & الابعاد \\
\hline \multirow{2}{*}{ دالة عند } & \multirow{2}{*}{$r r, q q$} & 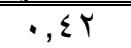 & $r, r$. & 0 . & الارباعي الادني & \multirow{2}{*}{ كفاءة تقديم } \\
\hline & & $\cdot, 17$ & $r, \vee T$ & 0. & الارباعى الاعلى & \\
\hline \multirow{2}{*}{ دالة عند } & \multirow{2}{*}{ r, } & • & $r, \vee q$ & 0. & الارباعي الادني & \multirow{2}{*}{ سهولة الوصول الخدمات } \\
\hline & & $\cdot, 1 \mathrm{~V}$ & $\varepsilon, 71$ & 0. & الارباعي الاعلى & \\
\hline \multirow{2}{*}{ دالة عند } & \multirow[b]{2}{*}{$r O, r}$. & $\cdot, \leq 1$ & $r, 19$ & 0. & الارباعى الادنى & \multirow{2}{*}{ الصحية في الوقاية } \\
\hline & & $\bullet, r$ & $\varepsilon, \cdot r$ & 0. & & \\
\hline \multirow{2}{*}{ دالة عند } & \multirow[b]{2}{*}{$r 7,19$} & $\cdot, \leqslant 1$ & Y, & 0. & الإباعى الادنى & \multirow{2}{*}{ ألمن وسلامة البيئة التدم فيها } \\
\hline & & • & $\varepsilon, Y V$ & 0. & الارباعي الاعلى & \\
\hline \multirow{2}{*}{ دالة عند } & \multirow{2}{*}{$Y 7, \leq 1$} & $\cdot, \mu q$ & $r, Y_{1}$ & 0. & الارباعي الادنى & \multirow{2}{*}{ العلاقة بين أعضاء الصريق الصحي } \\
\hline & & $\cdot, 1 \leq$ & $\varepsilon, \vee q$ & 0. & الارباعى الاعلى & \\
\hline \multirow{2}{*}{ دالة عند } & \multirow{2}{*}{ rT, } & • • & $1, \vee 7$ & 0. & الارباعي الادنى & \multirow{2}{*}{ الفيزيائية ووسائية التحنية } \\
\hline & & • & r,o & 0. & الارباعي الاعلى & \\
\hline \multirow{2}{*}{ دالة عند } & \multirow{2}{*}{ r,ג } & $1, \varepsilon$. & 17,10 & 0. & الإباعى الادنى & \multirow{2}{*}{ الدرجة الكلية } \\
\hline & & $\cdot, \wedge 9$ & $r \leq, 1$. & 0. & الارباعى الاعلى & \\
\hline
\end{tabular}

يتضح من الجدول السابق أن ثمة فرق بين الارباعي الادنى الارباعي الاعلى وهذا بدل على تمتع المقياس بقدرته على التمييز بين الأفراد الثبات: تم استخدام طريقة التجزئة النصفية وفيها يتم تجزئة المقياس الى نصفين وحساب قيمة لهئ

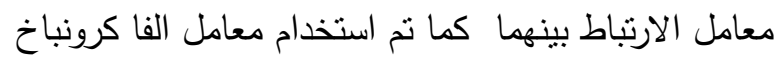
جدول(ץ): يوضح قيم معامل الثبات

\begin{tabular}{|c|c|c|}
\hline كعرونباخ الفا & (التجزئةة النصفية الثباتة) & \\
\hline$\cdot, \mathrm{VO}$. & $\cdot, 0 \vee 7$ & كفاءة تقديح الخدمة \\
\hline$\cdot, \wedge T Y$ & $\cdot, \mathrm{V} T \mathrm{~T}$ & سهولة الوصول الى الخدمات \\
\hline$\cdot, V \leqslant \vee$ & $\cdot, 009$ & توفير الرعاية الصحية في الوقت المناسب \\
\hline$\cdot, \vee \vee 1 \cdot$ & $\cdot, \mathrm{TVV}$ & آمن وسلامة البيئة التي تقدم فيها الرعاية الصحية \\
\hline$\cdot, 911$ & $\cdot, v \cdot 9$ & العلاقة بين اعضاء الفريق الصحى \\
\hline$\cdot, \vee r_{0}$ & $\cdot, \mathrm{T} \cdot \mathrm{V}$ & البنية التحتية الفيزيائية ووسائل الراحة \\
\hline$\cdot, 9 Y \cdot$ & $\cdot, \Lambda \cdot r$ & "الدرجة الكلية \\
\hline
\end{tabular}


يتضح من الجدول السابق أن قيم معامل الثبات باستخدام التجزئة النصفية ومعامل الفا

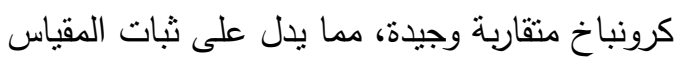
اختبار صحة الفرض الفرعي الأول: توجد علاقة ذات دلالة احصائية بين كفاءة تقديم الخدمة

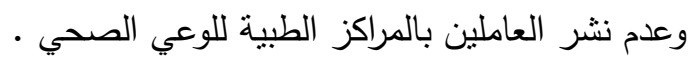

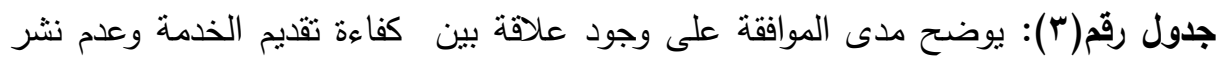
العاملين بالمراكز الطبية للوعي الصحي

\begin{tabular}{|c|c|c|c|c|c|c|c|}
\hline \multicolumn{2}{|c|}{ فترة الثقة } & \multirow[b]{2}{*}{ الدلالة } & \multirow[b]{2}{*}{ قيمة ت } & \multirow[b]{2}{*}{ الاتجاه } & \multirow[b]{2}{*}{ النسبي } & \multirow[b]{2}{*}{ الالعياري } & \multirow[b]{2}{*}{ المرجح } \\
\hline الأعلى & الأدنى & & & & & & \\
\hline$\Gamma, 1 \wedge$ & $r, \cdot r$ & $\cdot, \cdots$ & $v \varepsilon, r_{0}$ & 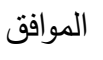 & $T r, \cdot$ & $\cdot, 09$ & $r, 1$. \\
\hline
\end{tabular}

يتضح من بيانات الجدول السابق أن آراء عينة الدراسة ايجابية حيث ان الوزن النسبي

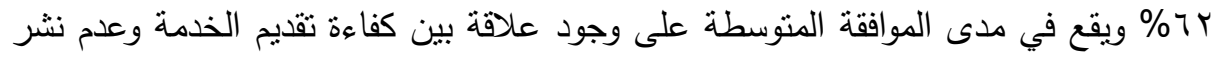

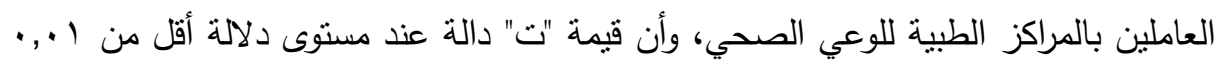

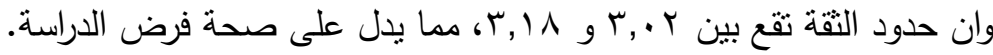
اختبار صحة الفرض الفرعي الثاني : نوجد علاقة ذات دلالة احصائية بين سهولة الوصول

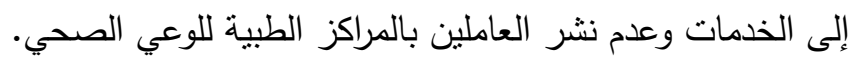
جدول رقم(§): يوضح مدى الموافقة على وجود علاقة بين سهولة الوصول إلى الخدمات

\begin{tabular}{|c|c|c|c|c|c|c|c|}
\hline \multicolumn{2}{|c|}{ فتترة الثقة } & \multirow[b]{2}{*}{ مستوية الدلائي } & \multirow[b]{2}{*}{ قيمة ت } & \multirow[b]{2}{*}{ الاتجاه } & \multirow[b]{2}{*}{ النسبي } & \multirow[b]{2}{*}{ الالاعياري } & \multirow{2}{*}{ المرجح } \\
\hline الأعلى & الأدنى & & & & & & \\
\hline$r, \vee \varepsilon$ & $r, 0 \varepsilon$ & $\cdot, \cdots$ & $V Y, \leqslant q$ & الموافق & $V Y, \Lambda$ & $\cdot, V \cdot$ & $\Gamma, \uparrow \varepsilon$ \\
\hline
\end{tabular}


يتضح من بيانات الجدول السابق أن آراء عينة الدراسة ايجابية حيث ان الوزن النسبي

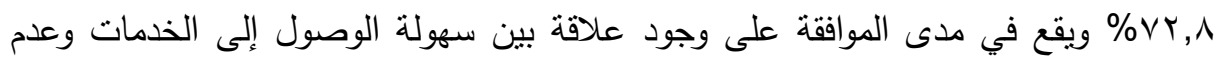
نشر العاملين بالمراكز الطبية للوعي الصحي وان قيمة "ت" دالة عند مستوى دلالة أقل من وند

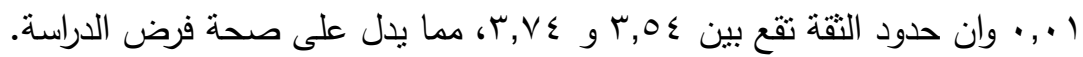
اختبار صحة الفرض الفرعي الثالث: توجد علاقة ذات دلالة احصائية بين توفير الرعاية الصحية في الوقت المناسب وعدم نشر العاملين بالمراكز الطبية للوعي الصحي .

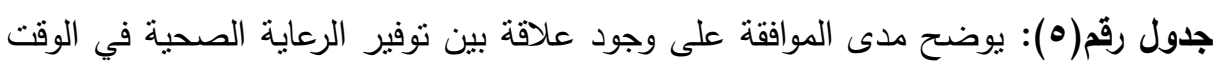

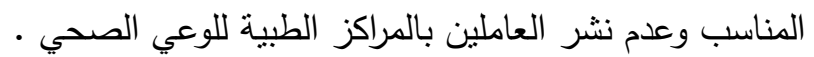

\begin{tabular}{|c|c|c|c|c|c|c|c|}
\hline \multicolumn{2}{|c|}{ فترة الثقة } & \multirow[b]{2}{*}{ مستوي } & \multirow[b]{2}{*}{ قيمة ت } & \multirow[b]{2}{*}{ الاتجاه } & \multirow[b]{2}{*}{ النسبي } & \multirow[b]{2}{*}{ المعياري } & \multirow[b]{2}{*}{ المرجح } \\
\hline الأعلى & الأدنى & & & & & & \\
\hline$T, Y T$ & $r, \cdot T$ & $\cdot, \cdots$ & 71,90 & الموافق & $T r, Y$ & $\cdot, V Y$ & $r, 17$ \\
\hline
\end{tabular}

يتضح من بيانات الجدول السابق أن آراء عينة الدراسة ايجابية حيث ان الوزن النسبي

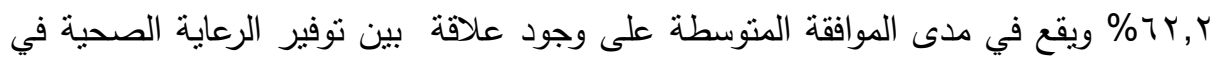

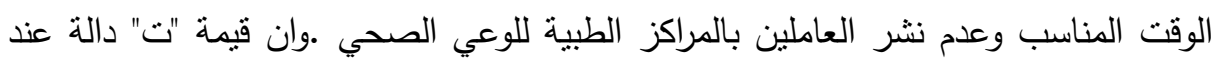

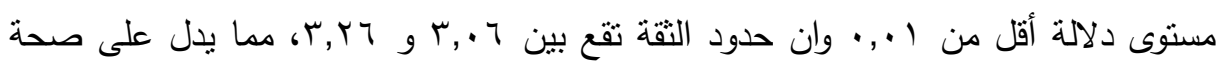
فرض الدراسة.

اختبار صحة الفرض الفرعي الرابع: توجد علاقة ذات دلالة احصائية بين أمان وسلامة البيئة

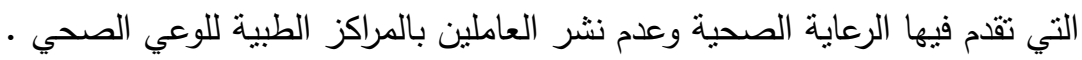
جدول رقم(7): يوضح مدى الموافقة على وجود علاقة بين أمان وسلامة البيئة التي تقدم فيها

\begin{tabular}{|c|c|c|c|c|c|c|c|}
\hline \multicolumn{2}{|c|}{ فترة الثقة } & \multirow[b]{2}{*}{ مستوي الدلائ } & \multirow[b]{2}{*}{ قيمة ت } & \multirow[b]{2}{*}{ الاتجاه } & \multirow[b]{2}{*}{ النسبي } & \multirow[b]{2}{*}{ المعياري } & \multirow[b]{2}{*}{ المرجح } \\
\hline الأعلى & الأدنى & & & & & & \\
\hline$r, \leqslant \vee$ & T, YO & $\cdot, \cdots$ & $71,0 \leqslant$ & الموافق & $T V, Y$ & $\cdot, V \vee$ & $r, r \uparrow$ \\
\hline
\end{tabular}


يتضح من بيانات الجدول السابق أن آراء عينة الدراسة ايجابية حيث ان الوزن النسبي

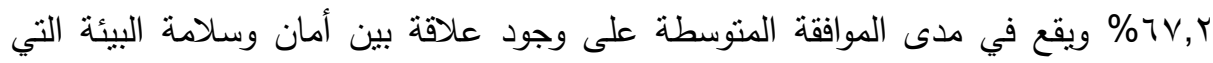

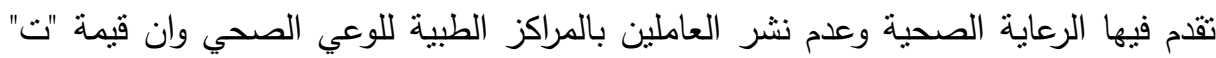

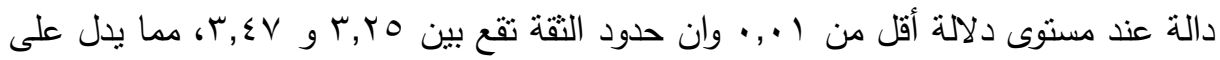
صحة فرض الدراسة. اختبار صحة الفرض الفرعي الخامس: نوجد علاقة ذات دلالة احصائية بين العلاقات بين أعضاء الفريق الصحي وعدم نشر العاملين بالمراكز الطبية للوعي الصحي. توجي. جدول رقم(V): يوضح مدى الموافقة على وجود علاقة بين أعضاء الفريق الصحي وعدم نشر بنر

\begin{tabular}{|c|c|c|c|c|c|c|c|}
\hline \multicolumn{2}{|c|}{ فترة الثقة } & \multirow[b]{2}{*}{ الدلالةي } & \multirow[b]{2}{*}{ قيمة ت } & \multirow[b]{2}{*}{ الاتجاه } & \multirow[b]{2}{*}{ النسبي } & \multirow[b]{2}{*}{ الالمعياري } & \multirow[b]{2}{*}{ المرجتح } \\
\hline الأعلى & الأدنى & & & & & & \\
\hline$\varepsilon, 1$. & r,qr & $\cdot, \cdot$ & 19,77 & الموافق & $\wedge r, \wedge$ & ז זד, • & $\varepsilon, .19$ \\
\hline
\end{tabular}

يتضح من بيانات الجدول السابق أن آراء عينة الدراسة ايجابية حيث ان الوزن النسبي

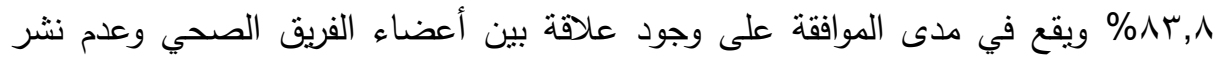

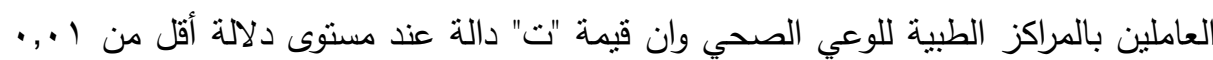

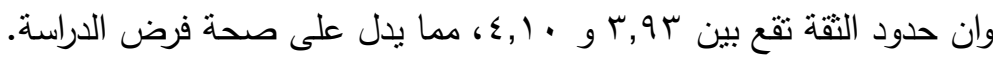
اختبار صحة الفرض الفرعي السادس: توجد علاقة ذات دلالة احصائية بين البنية التحتية

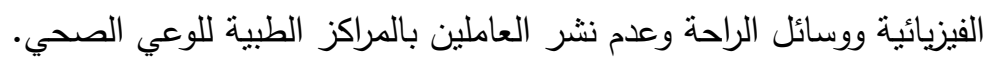
جلول رقم(^): يوضح مدى الموافقة على وجود علاقة بين البنية التحتية الفيزيائية ووسائل

\begin{tabular}{|c|c|c|c|c|c|c|c|}
\hline \multicolumn{2}{|c|}{ فَترة الثقة } & \multirow[b]{2}{*}{ الدلاكتي } & \multirow[b]{2}{*}{ قيمة ت } & \multirow[b]{2}{*}{ الاتجاه } & \multirow[b]{2}{*}{ النسبي } & \multirow[b]{2}{*}{ المعياري } & \multirow{2}{*}{ المرجح } \\
\hline الأعلى & الألدى & & & & & & \\
\hline r,AY & $r, T r$ & $\cdot, \cdots$ & צ & الموافق & $0 \leqslant, \varepsilon$ & $\cdot, V_{1}$ & $r, V Y$ \\
\hline
\end{tabular}


يتضح من بيانات الجدول السابق أن آراء عينة الدراسة سلبية حيث ان الوزن النسبي ؟, §०\% ويقع في مدى عدم الموافقة على وجود علاقة بين البنية التحتية الفيزيائية ووسائل الراحة وعدم نشر العاملين بالمراكز الطبية للوعي الصحي، وان قيمة ودودة "ت" دالة عند مستوى

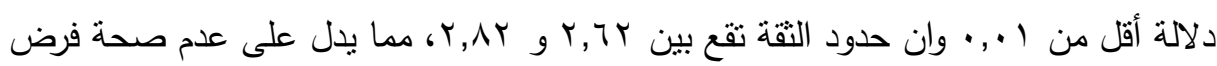

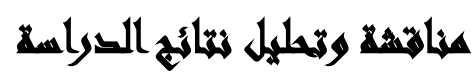

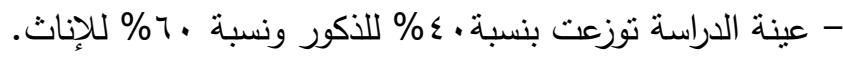
- عينة الدراسة توزعت حسب سنوات الخبرة الى نسبة ابك\% للفئة (V-1 سنوات) ونسبة

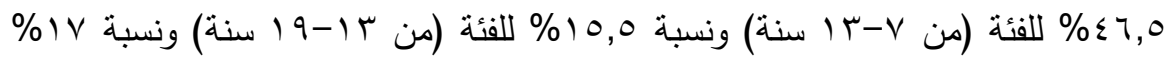
لفئة من (19 سنة فأكثر)

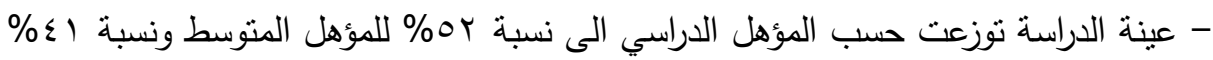
للتعليم الجامعي ونسبة v\% للاراسات العليا

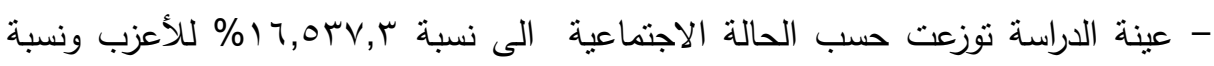

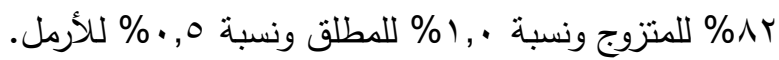

\section{المتهار هروضر التراسلة}

اختبار صحة الفرض الرئيسي : توجد علاقة ذات دلالة احصائية بين المشكلات الاجتماعية

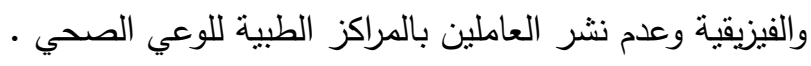

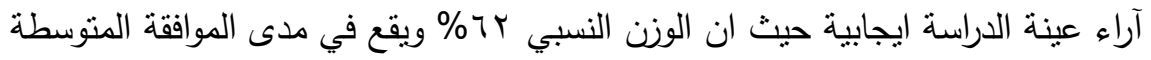
على وجود علاقة بين كفاءة تقديم الخدمة وعدم نشر العاملين بالمراكز الطبية للوعي الصحي،

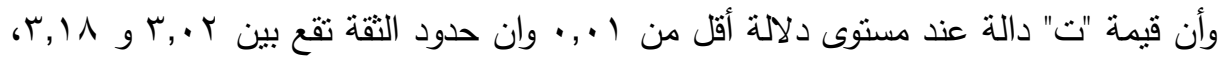
مما يدل على صحة فرض الدراسة. 
اختبار صحة الفرض الفرعي الأول: توجد علاقة ذات دلالة احصائية بين كفاءة تقديم الخدمة

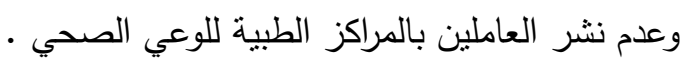

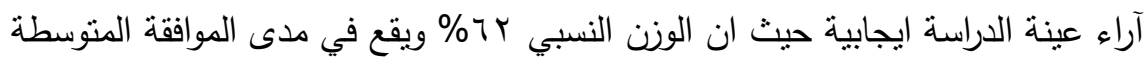

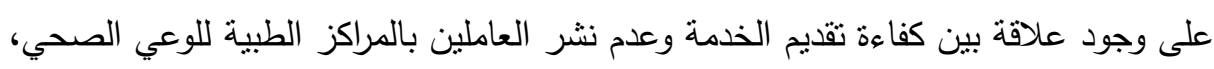

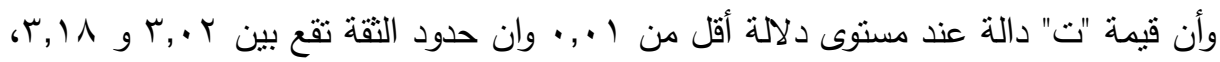
مما بدل على صحة فرض الدراسة. اختبار صحة الفرض الفرعي الثاني: نوجد علاقة ذات دلالة احصائية بين سهولة الوصول

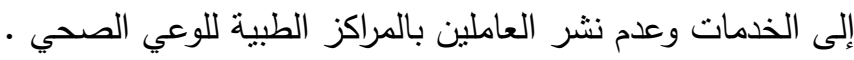

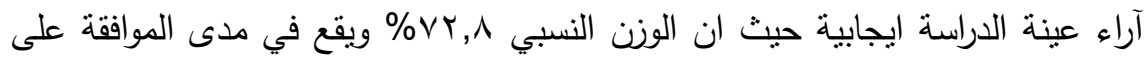

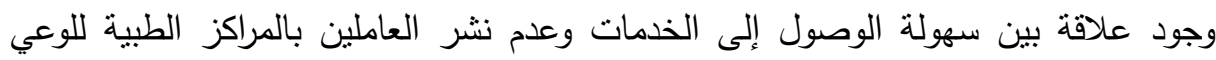

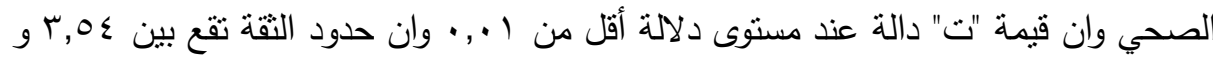
إخ اختبار صحة الفرض الفرعي الثالث: توجد علاقة ذات دلالة احصائية بين نوفير الرعاية الصحية في الوقت المناسب وعدم نشر العاملين بالمراكز الطبية للوعي الصحي .

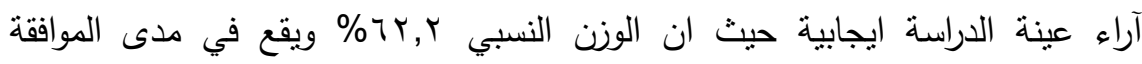

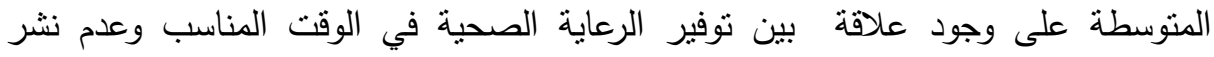

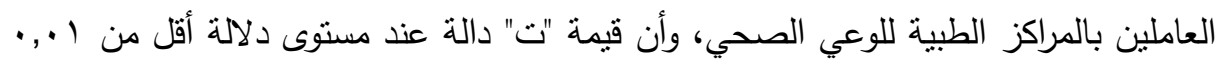

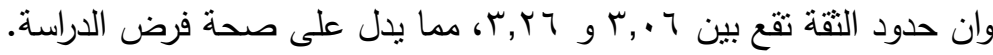
اختبار صحة الفرض الفرعي الرابع: توجد علاقة ذات دلالة احصائية بين أمان وسلامة

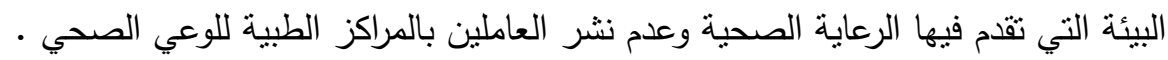

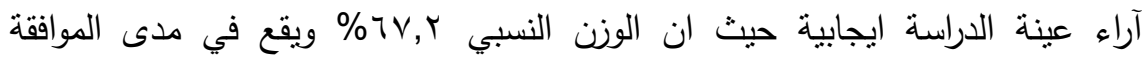

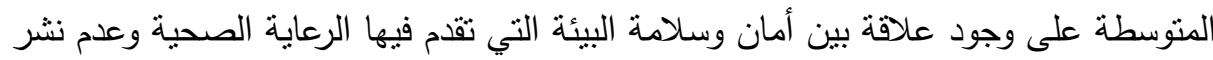

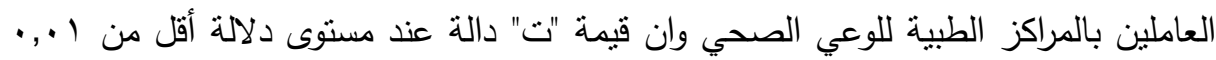

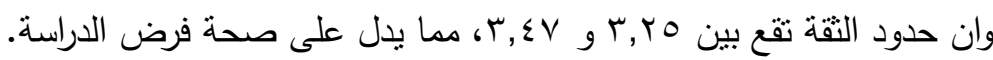


اختبار صحة الفرض الفرعي الخامس: توجد علاقة ذات دلالة احصائية بين العلاقات بين

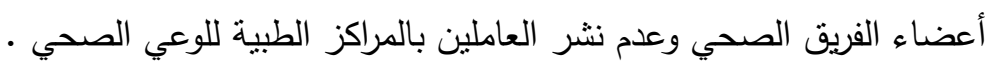

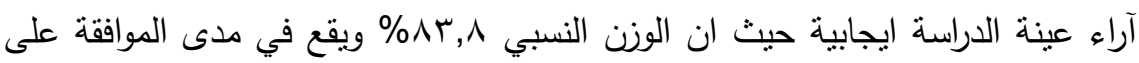

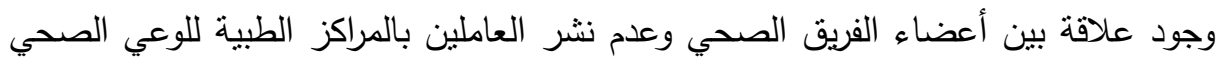

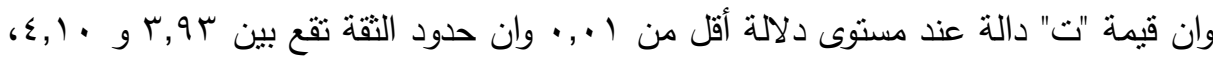
مما يدل على صحة فرض الدراسة. اختبار صحة الفرض الفرعي السادس: توجد علاقة ذات دلالة احصائية بين البنية التحتبة

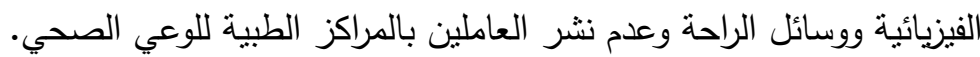

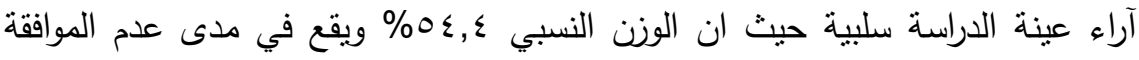
على وجود علاقة بين البنية التحتية الفيزيائية ووسائل الراحة وعدم نشر العاملين بالمراكز الطبية للوعي الصحي، وان قيمة "ت" دالة عند مستوى دلالة أقل من ا ب.,. وان حدود الثقة

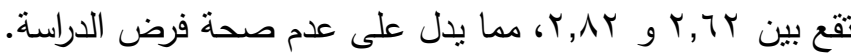

\section{تموسيامت الصراسة}

- نوفير مطبوعات ومواد إعلامية بالموضوعات التوعوية شديدة الانتثار .

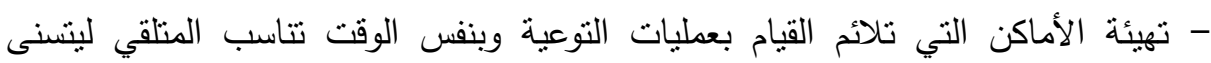

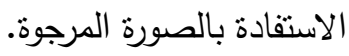
- الاهتمام بملاحظات متلقي الخدمة للاستفادة منها بعمليات التطوير • - توفير شاشات عرض بالمراكز لعرض المعلومات التوعوية وضمان وصولها لكافة المترددين

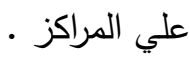

- إعطاء دورات تدريبية للطواقم الطبية للتعامل مع الجمهور . - منابعة المستجدات في السلوكيات والتوعية الصحية بشكل دوري لضمان وصولها للمترددين

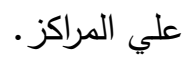

- ضرورة التعاون بين كافة الجهات المعنية لضمان تقديم خدمات التوعية بصورة أفضل.

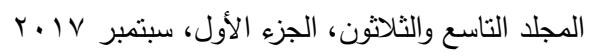




\section{المرايجs}

أحمد عبده عوض، أحمد عبد الرحيم السايح(1991): دراسات فى قضايا البيئة، معالجة

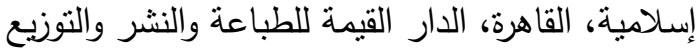

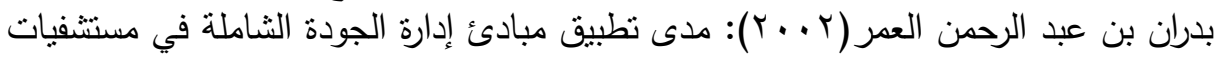

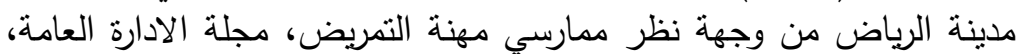

المجلد الثاني والأربعون، العدد الثاني، الرياض، داضئ، معهد الادارة

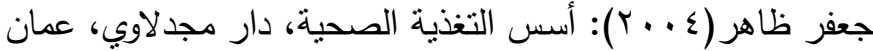

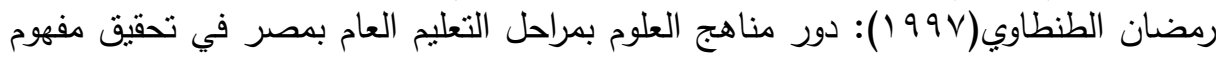

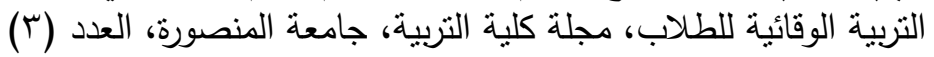

سهير عبد الله عبد الفتاح(1991) (1): التوعية الصحية والبدنية.

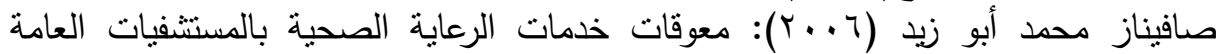

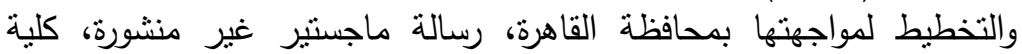

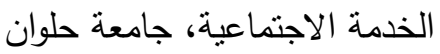

طلال يحى أبو شعيشع( ( . ب): الوعى السياسي لدى معلمي التعليم الابتدائي، جامعة طنطا،

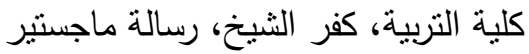

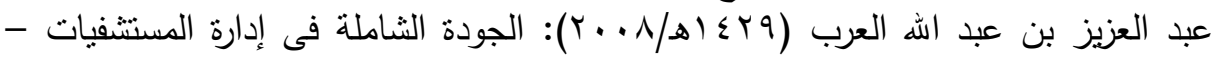

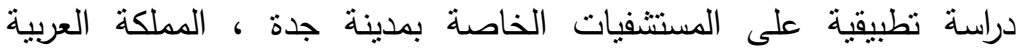

السعودية ، وزارة التعليم العالي، جامعة الملك عبد، كلية الاقتصاد والادارة.

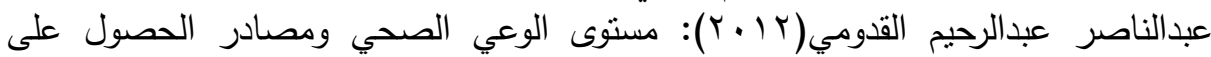

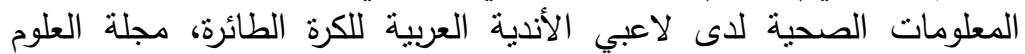

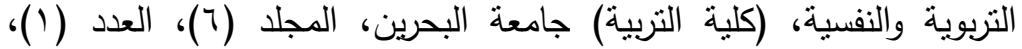
YTH-YYr

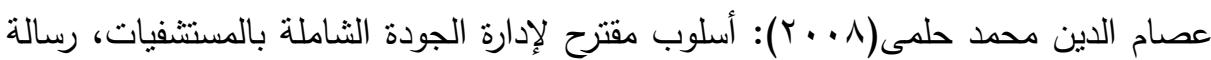

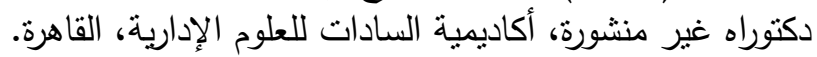

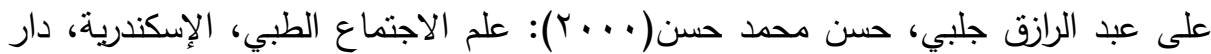

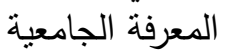

فخري شريف العلي(· • • ب): مستوى التقافة الصحية لاى الطلبة في نهاية المرحلة الأساسية

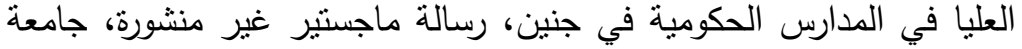

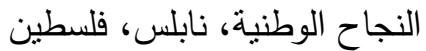

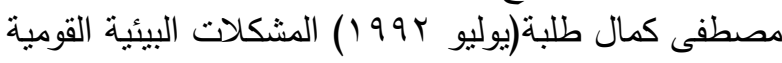


منى حامد على إبراهيم(9191 (19): برنامج مقترح لنشاط أندية أصدقاء البيئة وتأثيره على نتمية

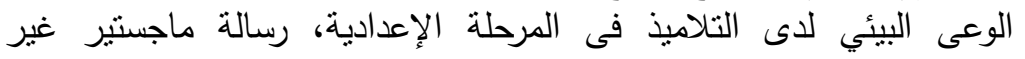

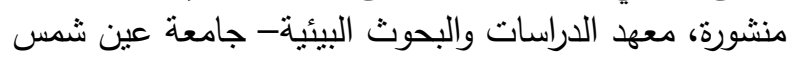

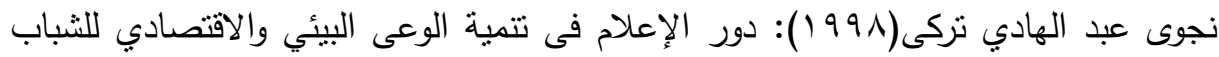

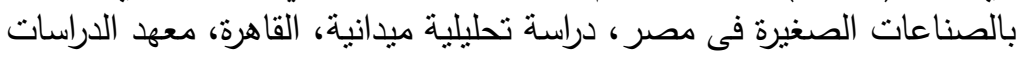

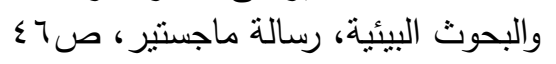

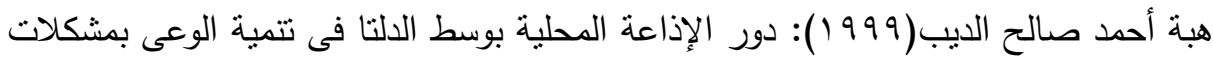

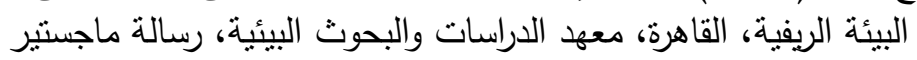

Andrulis,-Dennis-P; Brach,-Cindy;(2013) Integrating literacy, culture, and language to improve health care quality for diverse populations, American-Journal-of-Health-Behavior. Vol 31.

Hoare K; "Tackling infant malnutrition in The Gambia." Heath Visitor. 67(3)2012 .

Kelley lee(2002): Kent Buse: Health Policy in a Globalizing world, Cambridge, university press, University published.

Lottes Christine R ; (2009),Health knowledge \& behavior for years later. Pennsylvania University (ERIC, ED, 399229).

Louise-E Parker et al (Nov 2007): Balancing participation and expertise: A comparison of locally and centrally managed health care quality improvement within primary care practices, Journal; Peer-Reviewed-Journal, QualitativeHealth-Research. Vol 17(9).

Sewer, Victor E (2007): "Benchmarking in Hospitals: More Than a Scorecard", Quality Progress ; Aug, Vol, 40 Issue.

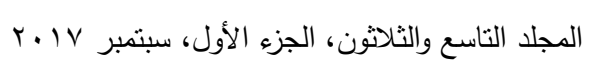


مجلة العلوم البيئية

معهد الدراسات والبحوث البيئية - جامعة عين شمس لمس

\title{
SOCIAL AND PHYSICAL PROBLEMS THAT \\ HINDER WORKERS IN MEDICAL CENTERS ON \\ PREVALENCE OF HEALTH AWARENESS \\ A FIELD STUDY ON SOME MEDICAL CENTERS IN \\ CAIRO
}

\begin{abstract}
Awad, M. I. ${ }^{(1)}$; Shoman, A. E. ${ }^{(1)}$ and Komsan, Samah, A.
1) Institute for Environmental Studies and Research, Ain Shams University 2) Faculty of Medicine, Ain Shams University
\end{abstract}

\begin{abstract}
The medical centers occupy a prominent position in health institutions based on the important role played by them and the many goals they have achieved. Their roles and therapeutic and awareness functions are part of the health services that increase their effectiveness and satisfy many of the needs of their beneficiaries. The study aims to identify the relationship between problems Social, physical and nondeployment of workers in medical centers for health awareness, this study belongs to the pattern of analytical descriptive studies and depends on descriptive analytical method using the sample survey method, and the study reached the following results: The study recommended the provision of publications and information materials on the topics of awareness and dissemination of information and the creation of places suitable for conducting awareness campaigns and the same. Time suits the receiver so that it can be used as desired.
\end{abstract}

